\section{Reconfiguraçóes da sociologia francesa contemporânea (1960-2000)}

Catherine Paradeise, Dominique Lorrain e Didier Demazière (dirs.). Les sociologies françaises: heritages et perspectivs (1960-2010). Rennes, Presses Universitaires de Rennes, 2015. 650 pp.

\section{Carlos Benedito Martins}

O complexo processo de globalização das sociedades contemporâneas, que direta e/ou indiretamente reverbera na produçáo do conhecimento acadêmico, assim como a progressiva constituição de uma comunidade sociológica global - segundo a expressão de Piotr Stompka (2010) - têm impulsionado diversas sociologias nacionais, situadas tanto em centros hegemônicos como em polos emergentes, a analisar a produção sociológica que vem sendo praticada nos seus respectivos países.

O livro Les sociologies françaises: heritages et perspectivs (1960-2010) insere-se no conjunto de trabalhos realizados por diversas sociologias nacionais que procuram (re)avaliar-se criticamente. Possui o mérito de cobrir uma lacuna sobre a autorreflexão da sociologia francesa, já que a última publicação que analisa a sua configuração ocorreu no final da década de 1980, no trabalho de Henri Mendras e Michel Verret (1988). Ao mesmo tempo, o livro tem o valor de reunir numa única edição uma série de referências bibliográficas relevantes sobre a história da disciplina no contexto francês que estavam dispersas em vários trabalhos elaborados ao longo do tempo.

A obra é o resultado do seminário Transmissions: une communauté en héritage. La sociologie et les sociologues français de 1970 à nous jours, que ocorreu em Paris, em 2013. O evento foi estruturado a partir de dois eixos. O primeiro comportou um recorte intergeracional, reunindo sociólogos seniores e juniores. Nascidos entre 1946 e 1952, muitos dos seniores estavam aposentados ou prestes a se tornar inativos no ano da realização do seminário, em função da legislação que regula o serviço público francês. Já os sociólogos juniores, nascidos na segunda metade da década de 1970, estavam próximos de completar quarenta anos de idade. A missão dos seniores e juniores era explicitar as condiçóes institucionais existentes no momento em que entraram na disciplina e os recursos teóricos e empíricos encontrados, de forma a fornecer informaçóes que permitiram aos autores do livro rastrear as transformaçôes de produção do conhecimento sociológico na sociedade francesa nos últimos cinquenta anos.

O segundo eixo foi estruturado a partir da seleção de quinze áreas temáticas da sociologia que existiam tanto na década de 1970 como nos anos posteriores, ou seja, aproximadamente os mesmos campos de investigação que permearam a trajetória acadêmica dos sociólogos seniores e juniores. Os responsáveis pelo seminário e coordenadores do livro ressaltaram que a seleção das áreas não teve a intenção de exaurir a extensão do campo de investigação da sociologia francesa, tarefa sabidamente impossível de ser levada a cabo. Os sociólogos seniores e juniores passaram, então, a analisar uma mesma área subdisciplinar da sociologia, examinando continuidades, rupturas e/ou renovaçóes em seus respectivos domínios de especialização. ${ }^{1}$

A interseção desses dois eixos possibilitou aos autores do livro abordar as dimensóes institucionais, intelectuais, teóricas, metodológicas e culturais do percurso da sociologia francesa e fornecer ao leitor um denso volume de dados sobre determinadas mudanças significativas ocorridas nas últimas cinco décadas. Nesse sentido, a convergência desses dois eixos conferiu originalidade ao livro, quando comparado com a análise da produção sociológica realizada em outros países. ${ }^{2}$

O trabalho contém mais de trinta capítulos, com a participação de autores como Christophe Charle, François Dubet, Alain Chenu, Martine Segalen, Margaret Maruani, Maryse Tripier, Pierre-Michel Menger, entre outros. Possui uma seção de discussão a respeito da sociologia francesa vista pela América do Norte, na qual Michèle Lamont realiza um diagnóstico da sociologia francesa contemporânea e Andrew Abbott e Étienne Ollion efetuam um exaustivo levantamento bibliográfico sobre a recepção da sociologia francesa na América do Norte, entre o período 1970 e 2009.

As exposiçóes realizadas nos capítulos do livro indicam que a sociologia francesa encontrava-se fragilizada institucionalmente por volta dos anos de 
1950; sua fraca presença no meio universitário estava voltada, fundamentalmente, a oferecer cursos para outras áreas de conhecimento na graduação. A Sorbonne - espaço central na disseminação da sociologia ensinada nas faculdades de letras - não conseguiu impulsioná-la e tampouco inserir a pesquisa empírica na disciplina. Os três professores que ocupavam a cátedra de sociologia na Sorbonne, Georges Gurvitch, Jean Stotzel e Raymond Aron, exploravam autores clássicos da sociologia e/ou apresentavam suas próprias concepçóes teóricas.

Foi somente em 1958 que a sociologia foi introduzida nos cursos de graduaçáo. Por meio da modalidade de licence, o estudante passou a ter acesso à disciplina durante os três primeiros anos do ensino superior. Um passo adiante foi dado em 1976, quando estudantes passaram a obter o título de agregation de sciences sociales, a partir de um competitivo exame nacional, que permitia ao agregé lecionar nas escolas secundárias ou em disciplinas nas universidades. O livro ressalta o trabalho desempenhado pela geração dos "refundadores" da sociologia, formada academicamente nos anos de 1940 em outras disciplinas, como filosofia e história, destacadamente na tradicional École Normale Superière (ENS), célebre celeiro de formação da intelectualidade francesa. Essa geração instaurou uma divisão do trabalho sociológico ao criar campos de especialização cujos respectivos líderes se tornaram referências obrigatórias por um longo período, mesmo após suas aposentadorias. Nesse sentido, a sociologia do trabalho foi conduzida por Alain Touraine e, secundariamente, por Jean-Daniel Reynaud e Jean-René Tréanton, a sociologia da educação por Viviane Isambert-Jamati, a sociologia urbana por Paul-Henri Chombart de Lauwe e Henri Lefebvre, a sociologia do lazer por Joffre Dumazedier, a sociologia rural por Henri Mendras, a sociologia da religião por François Isambert-Jamati etc. ${ }^{3}$

O alento da criaçáo dos cursos de graduação em sociologia - que logo em seguida se beneficiou da expansão do ensino superior francês - e a constituição de equipes de pesquisa propiciaram o aparecimento das primeiras revistas de sociologia, tais como Sociologie de Travail, em 1959, e tanto a Revue Française de Sociologie como o Archives Europènnes de Sociologie, em 1960. Nessa esteira, co- meçaram a surgir os primeiros espaços de formação acadêmica mais avançada, frequentados pela geração que nasceu entre 1946 e 1952 - denominada ao longo do trabalho de baby boomer - que deu origem aos sociólogos seniores, cuja análise constituiu um dos eixos do livro. ${ }^{4}$

O trabalho destaca que num espaço de cinco décadas o cenário da sociologia francesa modificou-se de forma sensível, em várias dimensóes, impulsionado pelas sucessivas ondas de expansão do ensino superior. A partir dos anos de 1970, os sociólogos recrutados nas universidades e em outras instituiçóes de ensino superior, bem como nos centros de pesquisa estatais, possuíam formação acadêmica nessa área disciplinar, em nítido contraste com períodos anteriores. A maioria recebera treinamento profissional nas universidades que tiveram um papel preponderante na expansão do ensino superior. Ocorreu também uma participação crescente das mulheres nos cursos de sociologia e, em seguida, no exercício da profissão, seja na pesquisa, seja na atividade de ensino. A participação de sociólogos nos centros de pesquisas estatais progrediu, embora num ritmo irregular, bem como na atividade docente: em 1970 havia não mais que uma centena de professores trabalhando no ensino de sociologia nas universidades, sendo que em 2011 esse número saltou para novecentos docentes. ${ }^{5}$

O livro ressalta a expressiva participação de sociólogos que exercem suas atividades profissionais distante do meio universitário e dos centros de pesquisas estatais, muitos deles com doutorado na disciplina. Segundo dados da Association Française de Sociologie mencionados no trabalho, no ano de 2015 essa sociedade científica contava com 1519 membros. A maioria trabalhava em ocupaçóes extra-acadêmicas, em empresas privadas, administraçóes regionais, coletividades territoriais e redes associativas, exercendo diversas funçóes, como gestão de recursos humanos de grandes empresas, intervenção em questôes urbanas, políticas de saúde, luta contra discriminação etc. ${ }^{6}$

A presença renovada da disciplina expressou-se também na ampliação dos espaços de debate científico. Por um lado, ocorreu uma proliferação de novas revistas especializadas, tais como Actes de la Recherche en Sciences Sociales em 1975, Sociétés Con- 
temporaines em 1990, Sociologie Pratique em 1999, Terrains et Travaux em 2000, Socio-Logos em 2006, Sociologie em 2010. Paralelamente, apareceram numerosas revistas voltadas aos subcampos temáticos da sociologia, várias delas disponíveis por meios eletrônicos. Também foi refundada a associação francesa de sociologia. Nessa direção, o trabalho destaca que a Société Française de Sociologie (SFS), criada no início dos anos de 1960, vinha definhando ao longo do tempo em função de acirradas disputas entre os defensores de uma sociologia voltada a fins práticos e os que desejavam imprimir uma dimensão crítica e militante à disciplina. As posiçóes antagônicas de seus participantes a respeito dos acontecimentos de 1968 aguçaram seus conflitos internos de tal forma que em 2011 ela contava tão somente com cinquenta membros. Em 2002, ocorreu a dissolução da SFS e uma assembleia geral, que reuniu 250 sociólogos, em Paris, decidiu refundar uma nova sociedade científica com uma designação ligeiramente diferente: Association Française de Sociologie (AFS).

O livro destaca o papel estratégico que a AFS desempenhou na reconfiguração da sociologia francesa contemporânea, cuja criação suscitou uma adesão de sociólogos de várias geraçóes, portadores de uma pluralidade de abordagens teóricas e de procedimentos de pesquisa. Sua dinâmica teve um impacto relevante no processo de crescente especialização dos campos temáticos da sociologia - fenômeno que não é específico da sociologia francesa -, uma vez que sua organizaçáo encontra-se estruturada a partir de cinquenta grupos de trabalhos, cobrindo uma ampla gama de objetos clássicos de investigação, além de temas emergentes. ${ }^{7}$

Essa maneira de organizar a produção acadêmica prolonga uma tradição de trabalho intelectual inaugurada pelos sociólogos franceses dos anos de 1950, baseada numa divisão do trabalho a partir de diferentes objetos de pesquisa. Nesse sentido, a AFS consolidou um modo particular de configurar o trabalho sociológico: a concentração em determinados objetos de investigação, um conjunto de especialistas organizados em equipes e/ou laboratórios de pesquisa, concentrados em seus respectivos campos de investigação. Dessa forma, a crescente segmentação da sociologia francesa seguiu uma rota inversa à proposta por Pierre Bourdieu - crítico severo da organização da disciplina a partir da soma de suas múltiplas especializaçóes -, que ao longo de sua carreira empenhou-se em estabelecer uma base teórica geral para a sociologia, capaz de analisar de forma transversal uma multiplicidade de objetos sociais. ${ }^{8}$

$\mathrm{Na}$ esteira das mudanças que ocorreram na sociologia francesa o conjunto de artigos do livro aponta para a existência, no momento atual, de uma multiplicidade de paradigmas teórico-metodológicos utilizados nas pesquisas que vem sendo realizadas. Paralelamente a esse fenômeno, verifica-se também um progressivo esgotamento das fortes oposiçóes entre escolas de pensamento, presentes no período entre 1970 e a segunda metade dos anos de 1990. Assinalam que, no contexto atual, dificilmente pode-se identificar algo equivalente à estruturação do campo sociológico a partir do quadriunvirato constituído por Bourdieu-Touraine-Crozier-Boudon, que marcou fortemente o campo da sociologia francesa naquele período. Isso náo significa dizer que os desacordos e rivalidades entre os seus respectivos continuadores tenham desaparecido e tampouco que inexistam novas tentativas de elaboração de esquemas gerais de interpretação. $\mathrm{O}$ que está em curso - talvez uma das transformaçóes mais significativas - é uma progressiva mutação das oposições paradigmáticas que estruturavam, em larga medida, o debate acadêmico em décadas anteriores e sua metamorfose em controvérsias teóricas e metodológicas mais específicas, intrínsecas a cada subcampo da sociologia francesa atual. Esse deslocamento das controvérsias na disciplina foi impulsionado por uma intensificação do número de sociólogos que se alojaram em áreas delimitadas de investigaçóes. Nessa direção, tendem a formular suas próprias lógicas de atividade, seus próprios debates teóricos e, no limite, inclinam-se a autonomizar suas áreas de investigação diante dos outros subcampos. A modalidade de disposiçáo do trabalho sociológico adotado pela AFS - uma forte descentralização, ancorada na existência de uma multiplicidade de grupos de trabalhos -fortaleceu essa transformação, que se encontra em pleno movimento.

Ao longo de suas páginas, o livro fornece um conjunto precioso de relatos sobre as condiçóes de entrada e os modos de socialização das duas gerações. Nessa direção, assinala que a geração de sociólogos nascidos entre 1946 e 1952 teve sua car- 
reira marcada pelas mudanças ocorridas no ensino superior e na pesquisa nos últimos quarenta anos, ou seja, pela massificação e pauperização das universidades francesas, a integração progressiva das unidades do Centre National de la Recherche de Scientifique (CNRS) nos estabelecimentos de ensino superior e também pelo conjunto de reformas educacionais. Como o processo de especialização estava a meio caminho, esses sociólogos puderam usufruir de uma relativa liberdade intelectual para realizar suas teses de doutorado ou futuros trabalhos, o que lhes permitiu colocar questóes mais amplas para investigaçáo e, ao mesmo tempo, circular com desenvoltura entre diferentes disciplinas, como história, ciência política, etnologia, economia etc., incorporando esse trânsito intelectual em suas produçóes.

Contrastando com esse panorama, a geração que nasceu na metade dos anos de 1970 encontrou diante de si um campo profissional mais estruturado e especializado, contando com cursos regulares de doutorado, com abundância de publicaçóes e com um meio acadêmico repleto de investigaçóes realizadas por sociólogos que tendem a se mostrar ciosos em preservar o domínio acadêmico em suas respectivas áreas de atuação. Diante dessas circunstâncias, a tarefa de explorar novos territórios de pesquisa tornou-se mais árdua, na medida em que o custo de entrada na atividade sociológica ficou mais elevado. Essa geração deparou-se também com profundas transformações institucionais de organização do trabalho sociológico que, distanciando-se de uma modalidade de artesanato intelectual, é cada vez mais realizado em espaços coletivos, expresso por meio de centros de pesquisa ou de laboratórios que se disseminaram nas últimas décadas inclusive em universidades mais modestas.

Essa nova realidade foi de tal forma impactante que o pertencimento a uma unidade de pesquisa passou a ser um marcador identitário na profissão. A entrada na carreira profissional ficou mais regulamentada e mais restrita por parte da administração universitária. Após a obtenção da tese de doutorado, o candidato a um posto de trabalho universitário - cada vez mais competitivo - precisa ser qualificado pelo Conseil National des Universités para poder candidatar-se ao cargo de maître de conferences, geralmente o nível docente mais disponível. Essa geração beneficiou-se do processo de globalização do ensino superior, que compeliu os sociólogos franceses a se integrarem crescentemente no espaço internacional da disciplina. E isso não apenas no espaço europeu, inclusive utilizando a língua inglesa nessas relaçōes, em nítido contraste com a geração anterior.

A leitura do livro sugere que, ao longo de cinco décadas, a sociologia francesa afastou-se de discursos metateóricos e passou a construir seus conhecimentos cada vez mais calcados em dados coletados a partir de uma multiplicidade de procedimentos de pesquisa, articulando de forma sistemática teoria e empiria. De certa maneira, essa postura aproximou-se da proposta de teoria de médio alcance, formulada por Robert Merton (1949). Isso não deixa de ser uma ironia, pois durante um extenso período essa proposição metodológica foi severamente criticada por vários sociólogos franceses. A crescente especialização de seus campos temáticos, reiterada em inúmeras passagens do livro, se por um lado permitiu a produçáo de conhecimentos mais sistemáticos, por outro acarretou uma perda de elaboraçóes intelectuais mais gerais, um dos traços mais visíveis de sua sociologia no plano internacional, expressa em conceitos como sociedade bloqueada, sociedade pós-industrial, senso prático, ator-rede, convenção e justificação etc.

$\mathrm{O}$ avanço da sociologia francesa trilhado, em boa medida, por meio de sua segmentação temática não deixa de apresentar desafios para sua audiência social. Nesse sentido, o livro destaca que cada área de especialização tende a criar seu próprio público-alvo, ou seja, seus consumidores restritos interessados numa determinada fração do conhecimento sociológico. Dessa maneira, ressalta que a sociologia vem perdendo paulatinamente sua capacidade de estabelecer uma comunicação com um público mais amplo, que, de certa forma, encontra-se motivado em compreender intelectualmente as transformaçôes que estão ocorrendo no mundo contemporâneo. Ao mesmo tempo, salienta que a sociologia depara-se, atualmente, com uma concorrência abundante de oferta de discursos variados, que oferecem explicaçôes abrangentes sobre a sociedade atual. Nessa direção, no plano acadêmico, a sociologia compete com 
os economistas, autolegitimados pela sofisticaçáo de seus modelos. É também confrontada pelo meio jornalístico, por uma multiplicidade de experts, e por blogueiros, que oferecem explicaçóes gerais com a aparência de seriedade intelectual.

O livro em questão representa uma contribuição exemplar da análise sociológica das mutaçôes recentes da sociologia francesa, na medida em que articulou de forma exitosa, sua história intelectual, institucional e cultural. Trata-se de uma leitura instigante e oportuna, que sugere pistas preciosas para a análise da disciplina em outros contextos nacionais, porventura da própria sociologia brasileira que, mutatatis mutandis, também se encontra num processo veloz de mudanças substantivas.

\section{BIBLIOGRAFIA}

ABBOTT, Andrew (1999). Department \& discipline: Chicago sociology at the one hundred. Chicago, University of Chicago Press.

ARON, Raymond (1983). Mémoires. Paris, Julliard.

BOURDIEU, Pierre (2001). Science de la science et réflexivité. Paris, Raisons d'Agir.

(1968). LE MÉTIER DU SOCIOLOGUE. PARIS, Mouton.

CALHOUN, Craig (org.) (2007). Sociology in America: an introduction. Chicago, University of Chicago Press.

CHARLES, Christhophe \& VERGER, Jacques (2012). Histoire des Universités: XII - XXI siècles. Paris, Presses Universitaires de France.

CHENU, Alain (2002). «Une institution sans intention: la sociologie en France depuis l'aprés-guerre». Actes de la rechercche en sciences sociales, 141-142: 46-61.

DROUARD, Alain A. (1982). «Réflexions sur une chronologie du développement des sciences sociales en France de 1945 á la fin des années soixante». Revue Française de Sociologie, 23 (1): 55-85.

HEILBRON, Johan (1991). «Pionniers par défaut? Les premières années du Centre d'études sociologiques (1946-1960)». Revue Française de Sociologie, 32 (3): 365-379.
JOURDE, Pierre (org.) (2007). Université: la grande illusion. Paris, L'Esprit des Péninsules.

HOUDEVILLE, Gérald (2007). Le métier du sociologue en France depuis 1945. Renaissance d'une discipline. Rennes, Presse Universitaire de Rennes.

LAZUECH, Gilles (1999). L'exception Française: le modèle des grandes écoles a l'épreuve de la mondialisation. Rennes, Presse Universitaire de Rennes.

MENDRAS, Henri \& VERRET, Michel (1988). Le champ de la sociologie française. Paris, Armand Colin.

MERTON, Robert K. (1949). Social Theory and Social Structure. Nova York, The Free Press.

PIRIOU, Odile (2007). La face cache de la sociologie: à la découverte des sociologues praticiens. Paris, Bélin.

STOMPKA, Piotr (2010). "One sociology or many?", in Sujata Patel (org.), The ISA handbook of diverse sociological traditions, Londres, Sage.

PATEL, Sujata (org.) (2011). Doing sociology in India: genealogies, locations and pratices. Oxford, Oxford University Press.

TREANTON, Jean-René (1991). «Les premièrs années du Centre d'études sociologiques (1946-1950)». Revue Française de Sociologie, 32 (3): 381-404.

\section{Notas}

1 As subáreas analisadas no livro foram: sociologia da estratificação social, família, escola, religiáo, trabalho, gênero, sociologia política, sociologia econômica, rural, urbana, migraçôes, saúde, arte e cultura, ciências e técnicas, comunicações de massa. O livro ressalta que, ao longo das cinco décadas, novos temas apareceram, como a questáo da conjugalidade no contexto da sociologia da família, as relaçóes interétnicas no âmbito da sociologia das migraçôes etc.

2 A propósito das análises empreendidas no contexto da sociologia americana, ver o trabalho de Craig Calhoun (2007), e da sociologia indiana, Sujata Patel (2011).

3 Com relaçáa à situação da sociologia francesa nos anos de 1950, ver Pierre Bourdieu (2001, pp. 187- 
193), Raymond Aron (1983, p. 343) e Alain Drouard (1982). Os trabalhos de Jean-René Tréanton (1991) e Johan Heilbron (1991) reconstroem os primeiros anos do Centre d'Études Sociologiques, que desempenhou papel importante na sociologia francesa nos anos de 1950.

4 O livro de Gérald Houdeville (2007) propicia uma análise detalhada da constituição dos novos espaços de pesquisa em sociologia francesa nos anos de 1960. O artigo de Alain Chenu (2002, pp. 48-51) fornece também informaçóes relevantes sobre a sociologia francesa no período de 1960.

5 O trabalho de Christophe Charle e Jacques Verger (2012, pp. 144-288) oferece um panorama da primeira e segunda ondas de expansão do ensino superior francês e também em outras partes do mundo, analisando suas consequências para a (re)organização do trabalho intelectual. Uma minuciosa análise sobre as grandes écoles é realizada no livro de Gilles Lazuech (1999). O contraste existente entre as condiçóes sociais subjacentes às grandes écoles e as universidades no contexto francês é realizado no trabalho coletivo organizado por Pierre Jourde (2007).

6 A situação dos sociólogos que exercem suas atividades profissionais distante do universo universitário é analisada no trabalho de Odile Piriou (2006).

7 Os cinquenta grupos de trabalho estão disponíveis no site da Association Française de Sociologie. Vale destacar que a AFS possui um periódico, denominado Socio-Logos, que tem dedicado alguns de seus números à profissão de sociólogo e ao processo de socialização dos doutorandos na disciplina.

8 Desde seus primeiros trabalhos até os que antecedem seu desaparecimento, Pierre Bourdieu (1968, 2001) procurou desrespeitar deliberadamente as fronteiras disciplinares e as especializações de objetos no interior da sociologia.

\section{CARLOS BENEDITO MARTINS é professor titular do Departamento de Sociologia da Universidade de Brasília (UnB). Foi visiting scholar em várias instituiçóes estrangeiras, entre as quais Universidade de Oxford, Universidade de Columbia, Universidade Livre de Berlim, Universidade de Hong Kong e Universidade Nacional de Cingapura. E-mail: carlosb@unb.br}

\section{ERRATA}

Na resenha Reconfiguraçóes da sociologia francesa contemporânea (1960-2000), com número de DOI: 10.17666/329312/2017, publicado no periódico Revista Brasileira de Ciências Sociais, 32(93): 1-6, na página 6 a informação sobre o autor não estava correta. $O$ texto correto segue abaixo:

\section{CARLOS BENEDITO MARTINS é professor titular do Departamento de Sociologia da Universidade de Brasília (UnB). Foi visiting scholar em várias instituiçóes estrangeiras, entre as quais Universidade de Oxford, Universidade de Columbia, Universidade Livre de Berlim, Universidade de Hong Kong e Universidade Nacional de Cingapura. E-mail: carlosb@unb.br}

\author{
Revista Brasileira de Ciências Sociais (2017) 32(93):1-6 \\ DOI: $10.17666 / 329312 / 2017 \mathrm{ER}$ \\ Elocation: e329312ER
}

